\title{
La mirada, el goce y el encuentro con los invisibles. A propósito de la enfermedad del Susto o Espanto en la cultura popular chilena
}

The look, the enjoyment and the encounter with the invisible. About the susto disease in the chilean popular culture

\author{
Mauricio García Peñafiel \\ Facultés Universitaires Saint Louis \\ Dirección postal: 43 Boulevard du Jardin Botanique - 1000 Bruselas - Bélgica. \\ Ce: garciae@fusl.ac.be
}

\begin{abstract}
Resumen. El artículo desarrolla una interpretación y una lectura, antropológica y psicoanalítica, de una enfermedad tradicional en Chile: la enfermedad del Susto o Espanto. A partir de material etnográfico y clínico, se analiza particularmente la fascinación y el espanto que -según los discursos recogidos- suscita el encuentro con la mirada de un espíritu que origina el Susto: la Fantasma. Esta descripción ambigua de los efectos de la mirada, está presente en muchos otros mitos y tradiciones de distintas culturas, donde la mirada es repetidamente tratada como vehículo del deseo. A partir del análisis del material recogido, se propone que si la mirada es prohibida por distintas tradiciones, es para sostener al sujeto en falta, evitando que se deslice al goce de hacer uno con el otro.
\end{abstract}

Palabras clave: etnopsicoanálisis, mirada, goce, fantasma, enfermedad del susto.

Abstract. The article develops an anthropological and psychoanalytical interpretation and reading of a Folk illness in Chile: the fright (Susto or Espanto) disease. From ethnographic and clinical material we specifically analyzes the fascination and the fear that - according to collected narratives - is suscitated by the encounter with the look of a spirit that provokes the fright: the Fantasma. This ambiguous description of the effects of the visual encounter is present in many other myths and traditions in different cultures, in which the "look at" is repeatedly treated as a vehicle of desire. From the analysis of the collected material it is argued that when the look is prohibited by different traditions, this is to keep the subject in need to avoid slipping to the enjoyment of forming a unity with the other.

Key Words: etnopsychoanalysis, look, enjoyment, fantasy, susto disease. 


\section{Introducción}

En Latinoamérica, como en muchas otras áreas del planeta, el trabajo clínico, psicoterapéutico, y el trabajo psicosocial con comunidades y etnias diversas, se enfrenta a menudo con discursos culturales enunciados por los actores para representar, dar orden y significar sus problemas o sufrimientos diversos. Aunque insuficientes, son innumerables los esfuerzos hechos para crear dispositivos terapéuticos que tomen en cuenta las lógicas culturales específicas, para instalar tratamientos o programas pertinentes y con sentido para los usuarios o actores sociales. Pero la tarea de desciframiento de nuestras especificidades culturales es, en cierto sentido, una tarea permanente.

Este artículo trata las cuestiones de la mirada y el goce a partir de la clínica con sujetos que traen interpretaciones tradicionales de su sufrimiento, que organizan su experiencia a partir de narraciones culturales que los preceden, y en las cuales la cuestión de la mirada es central. Se trata de un "desorden étnico", concepto tan caro a Devereux (1977), o de una "enfermedad tradicional" como prefiere plantear el Etnopsicoanálisis contemporáneo (Nathan, 1994). Se trata de la enfermedad del Susto o Espanto que describiré brevemente, tal como esta es relatada en el seno de la cultura popular chilena. Veremos cómo está interpretación tradicional organiza la experiencia del sujeto a partir del encuentro con un espíritu, con un invisible, donde la cuestión de la mirada es el punto central en torno al cual gravita el poder y el efecto de sujeción en que cae la "víctima" del susto. El material a partir del cual se realiza el análisis es clínico y etnográfico. Esta doble aprehensión del discurso tuvo su razón. No se puede suponer que la enunciación de estos discursos sea la misma cuando es el sujeto que viene a nosotros con una demanda de ayuda o de cura, a cuando somos nosotros los que vamos al terreno con una demanda de testimonios o de "información" si se quiere.

\section{El susto o espanto: breve descripción etnográfica}

Los testimonios que nutren esta descripción los recogí siguiendo los lineamientos de trabajo de campo etnográfico, durante el año 1996 en barrios populares de Santiago de Chile y en el sur del país. Por razones de espacio he optado por no citar a los informantes y contentarme con una suerte de resumen que intenta restituir lo escencial de sus testimonios.

El susto es un modo de ordenar el sufrimiento por su causa presunta y no por su "forma de presentación" sintomática. Los sujetos que pude atender o entrevistar, todos ellos hombres -nunca encontré una mujer víctima de susto- señalan que este desorden se contrae como consecuencia 
del encuentro con un espíritu femenino llamado la Fantasma. Un día, casi siempre en la noche, vieron a esta vieja mujer, la que generalmente es vista de espaldas, vestida con una gran túnica negra, siendo apenas visibles sus tobillos. Pero si se tiene la mala suerte de ver su rostro, entonces el sujeto queda asustado. Se trata de un rostro horrible, con enormes dientes, exhala fuego por la boca y tiene una mirada que hipnotiza: una vez tomado por esa mirada no se le puede esquivar ni evitar. Es por ello que la tradición aconseja no mirar el rostro de la Fantasma o incluso lo prohibe. Los efectos son diversos: un miedo generalizado, la sensación que la vida se detiene y se fractura, pérdida de la fuerza vital o incluso del alma, como veremos más adelante. Los síntomas más frecuentes son parálisis transitorias, mutismo e impotencia sexual, pero en rigor, un sujeto que padece este desorden puede virtualmente presentar cualquier síntoma del espectro psicopatológico o médico, y solo se lo reconoce en la sub-cultura como un "asustado" en la medida en que se supone un encuentro con la Fantasma como origen".

Como terapéutica espontánea los sujetos recurren a beber vino, pisco o agua ardiente. Según la tradición oral, esto sería la única "contra" para la Fantasma. Algunos afectados, como podrá adivinar el lector, llegan a ser alcohólicos, pero la mayoría queda en el estadio de bebedores excesivos. Lo importante es que para estos pacientes beber es la forma de curarse. El discurso explota aquí la ambigüedad de este significante en Chile, que por un lado significa "sanarse" y por otro "llegar al estado de ebriedad". En el plano significante se anudan salud y ebriedad, y de hecho esto es tal vez lo que subyace como lógica del acto del brindis, cuando decimos "isalud!"

Los sujetos afectados de "susto" que pude conocer, beben en el bar, y el bar popular en Chile es un espacio muy particular, siempre a media luz, organizado en mesas dispersas que funcionan como núcleos confesionales, donde se habla bajito. La manera de medir el tiempo es también particular: nadie va al bar una hora, sino que se va a tomar dos o tres botellas de vino. Se instaura una manera cualitativa de medir el tiempo, lo que recuerda al espacio del templo, el espacio ritual. Esta intuición está presente en la novela de Vargas Llosa Conversación en la catedral, donde después de un tiempo de lectura descubrimos que la Catedral es finalmente un bar. No puedo desarrollar con detalle esto ahora, pero la asociación en cuestión indica que tal vez estos pacientes intentan recrear un espacio ritual, de manera que el alcohol pueda ser eficaz simbólicamente. Intentan recrear en el bar las coordenadas de los dispositivos rituales de sus sub-culturas de origen, ya que

${ }^{1}$ Se pueden encontrar abundantes testimonios cercanos a lo aquí descrito en la obra de Vicuña Cifuentes (1947). Este autor ampliaba en ese entonces la pertinencia de este trabajo indicando la presencia de este mito en otras regiones de América Latina. La "Llorona" de Nuevo México, es descrita con características similares a la "Fantasma" chilena. Lo mismo ocurre parcialmente con la "Cegua" o "Cehua" en Costa Rica, la "Cigenda en San salvador, la "Cigua", la "Vieja", la "Sucia" o la "Llorona" en Honduras, entre otros. Evidentemente, nada garantiza que dichas similitudes persistan hoy. 
la gran mayoría de ellos son inmigrantes o hijos de inmigrantes de regiones rurales o semirurales del país.

Tan ardiente como el fuego que expulsa por su boca es el deseo sexual de la Fantasma. Algunos sujetos dicen haber sido violados por ella, otros la tratan de "puta", de insaciable, de perversa, u otros calificativos que hacen referencia a una sexualidad que sobrepasa todos los limites. Los sujetos perciben un exceso en el deseo de la Fantasma, exceso que figura lo sexual como devoración.

Se habla de ella a veces con temor y reverencia, y a veces riendo en tono de broma o ironía. A veces se habla de ella con la finalidad de censurar la sexualidad de los auditores, sobre todo los hijos, y a veces se le evoca para confesar a los otros lo inconfesable según las normas sociales y/o religiosas.

La mirada de la Fantasma es el centro de su poder, es desde ella que este espíritu "toma" al sujeto y lo posee. Los informantes la describen como una mirada fascinante y horrorosa al mismo tiempo. Suscita en el sujeto la experiencia de una seducción radical, acompañada por una suerte de "promesa de goce", para encontrarse luego con lo "siniestro"2. Esta mirada a doble valencia es uno de los núcleos sobre los que quisiera poner el énfasis, sabiendo que un discurso de esta índole permite muchos y variados ángulos de lectura, dando materia a pensar de modo incesante. Es por ello que no son substituibles por las teorías o las lecturas.

\section{El caso de Pablo}

Pablo llega desde Talca a Santiago a los 16 años buscando trabajo. Comienza como cargador, luego trabaja como recolector de uvas y finalmente, con la ayuda de un primo, es contratado en una empresa textil. Tiene 34 años cuando nos encontramos.

"Me duele todo el cuerpo, los huesos, me cuesta dormir y ando con poco ánimo. Por eso la Dra. me recomendó venir aquí". Agrega que hay momentos donde siente una angustia horrorosa, se paraliza, "pero es solo de vez en cuando". Al pasar, menciona algunas dificultades con su ex-mujer vinculadas a la muerte de su madre hace unos años. No habla mucho, "me cuesta hablar". El peso de esta dificultad se hace sentir en el dispositivo.

Introduzco el dibujo, y hablamos de ellos. Dibuja una luna con unos enormes dientes. Le pregunto porqué los dientes, y dice: "Porque con la media luna los espectros aparecen". Le digo que esa luna me hace pensar en la Fantasma. Esta riesgosa interpretación lo decide a decir algo que no había dicho ni a la psiquiatra ni a mí, porque pensaba que ignorábamos las

\footnotetext{
${ }^{2}$ En el sentido que Freud (1919) daba a este concepto, refiriéndolo a la experiencia de encontrarse ante algo extraño y desconocido al mismo tiempo que familiar. El término alemán Das Unheimliche es portador de esta doble significación y es difícilmente traducible al español.
} 
"enfermedades secretas", las "cosas antiguas": "Yo no estoy enfermo, yo tengo el susto, me tiene agarrado la Fantasma".

A partir de ese momento la situación cambia. Pablo comienza a hablar y recurre cada vez menos al dibujo. Mi reconocimiento del discurso cultural instala la transferencia y el comienza a llamarme "entendido", que en jerga popular significa algo cercano a curandero, pero entiendo que se trata de un significante local para señalar la posición del "sujeto supuesto al saber"3.

Poco antes de separarse de su mujer, hace dos años, "me encontré con la Fantasma en la calle. Antes tuve sueños con ella, pero nunca pensé que tal encuentro pudiera producirse". Describe el encuentro como una "visión fuerte". Pese a la obscuridad "vi sus horrible dientes y esos ojos insoportables". No recuerda que pasó después, pero está seguro que la Fantasma hizo de todo con él, incluidas relaciones sexuales. Vuelve en sí mismo y se encuentra botado en la calle, con sus ropas rasgadas, sudando y con los ojos hinchados. Le tomó horas llegar a su casa pues se desorientó.

Su mujer no creyó su historia, increpándole de haberse ido de parranda. No quiso hablar con médicos por temor a ser considerado loco e internado. Habló con algunos amigos y una vieja mujer de su barrio. Todos estos interlocutores reconocieron (diagnosticaron) su estado como el susto, diciéndole que la "contra" era tomar. "Desde entonces me sostengo de la mamadera" - dice. No había querido hablar de esto por temor a ser considerado alcohólico.

Desde este encuentro, Pablo se siente desesperado, en el temor y temblor permanente: "mi vida se rompió en dos y se detuvo".

Pregunto: ¿Cuándo empezaron los sueños previos al encuentro con la Fantasma? "Pocos meses después de que murió mi madre". Su esposa se opuso a que él fuera al entierro y se limitó a enviar flores y escribir una carta a la familia. Desde hace años que no visitaba a los suyos. "No debí hacer eso, no es bueno olvidar a la familia y la propia tierra". Piensa que es por este olvido que la Fantasma lo buscaba en sus sueños.

Junto con los sueños habían comenzado los dolores a los huesos, que se acentuaron después del encuentro con la Fantasma. Le dolían mucho las articulaciones y tenía dificultades en una serie de operaciones cotidianas como subir y bajar escaleras, vestirse, cargar cosas pesadas, etc. "Sentía que mi cuerpo pesaba el doble", y al decir esto Pablo recuerda un sueño de ese período: "veo el esqueleto de mi madre en un ataúd, vestida con el vestido de novia de mi ex-mujer". Al terminar de narrar el sueño me pregunta si escuché el ruido que hicieron sus rodillas. No - le digo- pero me quedo

\footnotetext{
${ }^{3}$ Lacan (1991) plantea este concepto para ubicar lo esencial de la transferencia que da lugar al trabajo psicoanalítico. El paciente, en tanto le falta el saber respecto de su síntoma ("ino entiendo lo que me pasa!") atribuye este saber al analista. Esta transferencia simbólica (y no imaginaria) funciona como "motor del análisis", como decía Freud.
} 
pensando qué es lo que había que escuchar. Pienso en una identificación con la madre muerta, en un duelo imposible.

Pero él insiste en hablar de posesión, no de una perdida, sino de un exceso. Entiendo que este discurso le permite hablar de los duelos que articulan su vida, pero bajo la estrategia narrativa de la posesión ${ }^{4}$, hasta su cuerpo, su esqueleto.

Nunca interpreté la Fantasma, ya que es el operador cultural que le permite asociar. Si interpretamos el dolor de huesos: "ud. lleva el esqueleto de su madre a cuestas porque no puede despedirse de ella". Su madre le había dicho que cuando uno no puede despedirse de alguien hay que conservar algo de esa persona, aunque sea una basurita que dejó olvidada: los huesos.

Me llama por teléfono para pedirme que interceda ante la administración del hospital pues, al pagar, no le dieron todo el vuelto la última vez que vino. Le digo que para eso no necesita de mi mediación, que puede dirigirse directamente a la caja.

La sesión siguiente me cuenta que no pasó por la caja porque finalmente no sabe si pagó de más o de menos. Le digo: No sabe si le deben o si ud. es el deudor, porque aun no ha podido ser un deudo". Pablo llora serenamente. Entiendo que es en esta deuda donde necesita mi mediación, lo que había sido enunciado por teléfono, pero desplazado a una cuestión de otro orden.

Después de esto va a Talca, visita la tumba de su madre, le habla, pasa por la posición de deudo y los síntomas empiezan a remitir. Duerme mejor y recupera el gusto por la vida. Pero según Pablo, yo tenía la "sangre fuerte" y es por eso que la Fantasma lo dejó en paz.

Hacia el final de trabajo, cuenta que visitó a su ex-mujer. Salió al patio y el pasto estaba tan crecido que no podía ver unos rosales que recordaba haber plantado hacía mucho tiempo. "Corté el pasto seco, sacando las malezas, enterrando mis dedos hasta las raíces, sacándolas una a una, hasta que encontré los rosales". Bella metáfora de lo que habíamos hecho. Sacar la hierba seca, los esqueletos muertos para dejar lugar a lo que de vivo había en él.

Ya no piensa en la Fantasma como un ser horroroso, "es como si sus ojos fueran los míos" - dice. De una cierta forma, la Fantasma funcionó como Otro a través del cual Pablo pudo hacer el camino del duelo, desenterrar algunas raíces y apropiarse parcialmente de su historia. En cierto sentido la Fantasma le había permitido conocerse o simplemente decirse.

\footnotetext{
${ }^{4}$ Esta vertiente de la cuestión la desarrollé en otro artículo (García, 2000).
} 


\section{La probibición de mirar como limitación del goce}

Es enigmático que el otro encarnado por la Fantasma sea ante todo una mirada, una mirada que petrifica, que "agarra", que espanta en una dinámica de posesión (que enmascara una pérdida). ¿Qué hay de tan espantoso en la mirada de la Fantasma como para que sea prohibido mirarla? Esta es una cuestión esencial. ¿Qué hay en el fondo de la mirada que la hace capaz de vehicular el mal? ¿Qué es lo que se encuentra en la mirada del otro y que es capaz de hacer de ella una metáfora tan fuerte del agente del sufrimiento? ¿Cuál es el fundamento de las prohibiciones que pesan sobre la mirada? ¿Qué es lo que hay de tan terrible a ver, para que estas representaciones culturales (y de tantos otros mitos) intenten escondérnoslo al tiempo que nos lo revelan? ¿Por qué es sobre la mirada, el ver y ser visto, que recae una gran parte de lo prohibido en estos discursos? Pulsión escópica, escopofilia, epistemofilia, son conceptos que no bastan para dar cuenta de la atracción de lo que se esconde, de la fascinación mortífera temida y esperada. Es verdad que la sexualización de la mirada permite comprender la vergüenza, la culpabilidad y la incomodidad que se presentan al momento de ver lo que debió quedar velado, pero es una perspectiva insuficiente.

$\mathrm{Al}$ interior del psicoanálisis encontramos dos grandes perspectivas sobre la cuestión de la mirada: a) la mirada en tanto pulsión a ver, desarrollada por Freud y más recientemente por Gérad Bonnet, y, b) la mirada en tanto objeto del deseo, desarrollada fundamentalmente por Lacan. Navegando entre ambas intentaré construir un camino para discernir lo que se dice en el susto sobre este enigma de la mirada anhelada y prohibida.

Para entrar en esta problemática de la mirada hay que darse cuenta que la experiencia contemporánea está fuertemente influenciada por la concepción de la óptica, desarrollada en lo esencial en el siglo XVII. Aunque no la conozcamos muy bien, parece evidente a todos actualmente que la visión es provocada por rayos luminosos refractados por el objeto que miramos, los que luego llegarían al ojo dando lugar a mensajes transmitidos al cerebro.

Sin embargo, en la mayor parte de las culturas tradicionales, y en las de la antigüedad occidental, constatamos una ausencia de la noción de rayos luminosos emanados del objeto, y encontramos más bien la idea de un rayo que emana del ojo (Simon, 1988). Probablemente es esta la razón por la que se ha podido constatar que la mirada está ausente de los trabajos fisiológicos y solo aparece en estudios más específicamente psicológicos y filosóficos referidos a nociones como "atención deliberada" o "intencionalidad" (Flavigny, 1987).

La concepción de la óptica es parte de los saberes populares en la cultura en Chile. Pero en el momento de hablar de la mirada en el contexto de la brujería o del susto, la idea de un registro pasivo de estímulos parece ser 
improbable para los actores sociales, como si la óptica chocara contra un muro que exige algo más. La mirada envidiosa, el mal de ojo y la mirada "asujetante", hablan de la mirada como algo que tiene lugar antes de lo que les es propuesto, llegando incluso a presentar y recrear invisibles, como el espíritu de la Fantasma.

Mirar o ser mirado por la Fantasma parece comportar una suerte de contacto extraño, a la vez intenso y peligroso. Los actores hablan de la mirada como una experiencia donde la información, el transporte de la información y la toma de conciencia son indisociables. La distancia entre lo visto y el que mira parece reducirse, lo que va contra nuestros hábitos mentales condicionados por la óptica. Pero precisamente, la vivencia de la mirada como contacto es lo que la hace propicia a funcionar como "vehículo del deseo", como sostiene el psicoanálisis ${ }^{5}$. Como siempre lo planteó Freud, las nociones populares y las de la antigüedad, resuenan y preceden a lo que el psicoanálisis nos enseña sobre las raíces inconscientes de todo lo que se trama en torno al acto de mirar.

Cuando los sujetos me hablaban de su encuentro con la Fantasma, los vectores de mirar o ser mirado se confundían, como si la distinción entre el activo y el pasivo no fuera esencial para ellos. Enunciados como "Vi a la Fantasma" o "La Fantasma me miró", parecían representar la misma situación. Vale la pena aproximar esto al pensamiento de la antigüedad. Platón pensaba que el acto de visión consiste en un encuentro o mezcla de dos flujos, de tal suerte que mirar o ser mirado son las dos caras de una misma situación, y se pondrá el acento en uno u otro según las circunstancias. Otro ejemplo griego es el rol jugado por la visión de Atena en el mito de Tiresias. "La visión de la diosa" es una fórmula ambigua, pero que testimonia de una ambigüedad inherente al pensamiento griego sobre la visión, en el cual, "en una total reciprocidad del ver y ser visto, percibir a un Dios es equivalente a caer bajo su mirada, como si, al final de cuentas, no viéramos nada mejor que el ojo del otro, como si en cada ojeada, todo se jugara entre dos miradas" (Loraux, 1982, p.108) ${ }^{6}$.

Durante siglos los griegos pensaron que contemplar la imagen de una divinidad podía causar la ceguera y el ser mirado por una de ellas podía causar la locura. Anclado en una tradición distinta, el texto bíblico insiste en la prohibición de ver el rostro de Yahvé. En el Éxodo le dice Dios a Moisés "tú no podrás ver mi rostro, ya que el hombre no podría verme y sobrevivir" (Éxodo: 33, 20). Más abajo, Dios anuncia que solo se dejará ver de espaldas: "Luego yo alejaré mi mano y me verás de espaldas; mi rostro no puede ser visto" (Exodo: 33, 23). En relación con la Fantasma encontramos la misma

\footnotetext{
${ }^{5}$ Para una aproximación clínica de esta idea, ver el libro de Lucien Israel (1994).

${ }^{6} \mathrm{La}$ traducción es del autor. Es el caso, en lo que sigue, de todas las citaciones en que el original está referido en Francés en la bibliografía.
} 
prohibición, solo se la puede ver de espaldas, su rostro debe ser sustraído a la mirada, a riesgo de caer en el espanto ¿Qué hay en el fondo de la mirada que la hace capaz de producir tales efectos?

Lacan nos ha habituado a pensar la mirada y la voz como paradigmas fundamentales del objeto $a$. Sin embargo la mirada tiene a veces en su obra más peso en tanto paradigma de este objeto. Tal vez esto se relacione con el hecho de que en las representaciones culturales encontramos también una preeminencia de la mirada como agente del sufrimiento.

El hecho es que en mi material, la mirada y la voz no ocupan el mismo lugar. En el susto, la voz no tiene ninguna incidencia, mientras que la mirada, la mirada del otro, es el canal a través del cual viene el sufrimiento. Esta asimetría entre mirada y vOz encuentra esclarecimientos relevantes en la metapsicología freudiana. La voz es pensada por Freud del lado de los efectos del ideal del yo, mientras que la mirada es pensada del lado de la pulsión. Hay una pulsión escópica, dice Freud, peno no una "pulsión vocal". Si solo la pulsión puede ser causa en lo psíquico, la tradición y la metáfora tendrían razón en presentar la mirada y raramente la voz - a excepción del canto de las sirenas y otros mitos análogos - como causa de la locura, del infortunio y de la muerte.

La mirada penetrante de la Fantasma es hipnotizante, alienante y, por lo tanto, aunque fascinante hay que evitarla. Pero una vez tomado y preso de esa mirada el sujeto no puede nada contra ella. "No poder hacer nada" contra esa mirada implica no poder nada contra el deseo de la Fantasma. Tomado por su deseo, la víctima deviene el objeto de su goce, lo que es a veces narrado explícitamente bajo la figura de la violación sexual. La prescripción de no mirar, o de solo mirarla de espaldas, está destinada a rodear la faz del Otro, para no exponerse a su deseo y evitar la desorganización del sujeto. Los síntomas que van a asediar al asustado dan cuenta de este desmoronamiento: pierde el habla, sufriendo a veces de un mutismo que no es fácil ubicar del lado de la histeria pero al menos del lado de la conversión. Todo ocurre como si a un exceso de curiosidad, a una mirada que no se somete a la prohibición, le siguiera una pérdida transitoria, una falta de palabra. Si las culturas precolombinas teorizaban esta pérdida en el susto como "vuelo del alma", es porque la palabra era pensada como la vertiente más sensible del alma humana.

Nunca he encontrado un asustado que sufra de ceguera conversiva, lo que sugiere que aunque la transgresión y el goce prohibidos se encuentran del lado de la mirada, la falta consecuente se instala en otro registro, en la palabra o en la motricidad. De hecho la parálisis del órgano fonatorio, de las piernas, los brazos, y también la impotencia sexual, son los síntomas más frecuentes del susto, siempre transitorios. Tenemos entonces que la falta de palabra, y la falta en el goce sexual, parecen instalarse como una suerte de compensación del exceso a nivel de la mirada. 
Pero la víctima de susto podrá retomar la palabra luego. El momento de la parálisis y del mutismo hunde al sujeto en el espanto más radical para luego iniciar algunas vías de ligazón a través de los intentos de reconstrucción ritual: es lo que encontramos en la construcción del bar popular.

\section{Mirada, seducción, captación imaginaria y espanto}

A la Fantasma se la encuentra en las calles, como los navegantes de antaño cruzaban a las Sirenas en su ruta. Detrás de su voz, detrás de la fascinación que suscitaban sus cantos, las sirenas escondían también una figura monstruosa de lo femenino. La Fantasma fascina no con su voz sino con su mirada, como Medusa que llevaba "la muerte en los ojos" -según la expresión del helenista Jean-Pierre Vernant (1997). Sus ojos "tomaban” al sujeto, cayendo este en una fascinación terrorífica. ¿Cómo no pensar aquí en la seducción que la mirada y lo escópico implican en lo inconsciente?

Si nos situamos del lado del ojo de la víctima, ¿qué ve esta más allá de la figura? Una mujer horrible pero fascinante. Fascinante no por sus rasgos sino por la exhibición descarnada que ella hace de su deseo, lo que le da "fuerza" a su mirada.

Si atendemos a la mezcla de rasgos femeninos y masculinos de esta figura, podríamos reconocer a la "figura combinada", lo que evoca a su vez la escena originaria. Pero hay algo más radical en la experiencia de las víctimas que señala esta incidencia: el hecho de que se trate de una visión impúdica del deseo del Otro. Si pensamos en la escena originaria descubierta por el Psicoanálisis, constatamos que para el ojo de esta escena se trata de un cuadro en que el sujeto queda literalmente estupefacto ante un espectáculo: la exhibición del deseo del otro. El sujeto se sitúa en tanto objeto de ese deseo que contempla y así es seducido. Pero esta seducción comporta una trampa, ya que el sujeto es captado por una imagen de la cual no puede abstraerse más. Análogamente, la seducción de la Fantasma consiste en una captación de la mirada de la víctima que extravía al sujeto. Lo extravía de sí mismo y lo extravía del resto de las imágenes del mundo (el mundo se le presenta roto), para encerrarlo en una imagen única, aquella que le ofrece la seductora. Esta mirada de la Fantasma funciona también como una suerte de espejo al cual el sujeto queda adherido al punto de despertar una serie de huellas sensoriales: el olor de la Fantasma se le pega a la piel y le es imposible sacarse de la cabeza su imagen. El encuentro se desarrolla en un clima de unheimlich, entre fascinación y espanto. El registro tópico en que se inscribe el encuentro hace que el sujeto encuentre la revelación de su goce en un "afuera interior", en la extimidad.

Es interesante notar que todo el cuerpo de la Fantasma esta velado, salvo su rostro y sus ojos. Es por la vía escópica y no por sus formas que se 
opera esta seducción radical que implica la exhibición desnuda del deseo del Otro. El cuerpo de la Fantasma esta velado, cubierto, pero su deseo está descubierto. El dominio del otro se efectúa aquí a través de la mirada. El que mira, una vez que es mirado por la Fantasma, no puede desviar la mirada. En la escena primaria es concebible que el sujeto pueda irse, dejar el espectáculo, ya que es él quien mira. Pero en el cruce de miradas, ¿quién es mirado? El sujeto que mira a la Fantasma es al mismo tiempo mirado por ella: el espectáculo se encuentra en ambos lados, y el ojo es apenas una débil cortina para separar ambas escenas: interior y exterior, ¿qué sentido pueden tener estos conceptos en este encuentro?

Comprendemos que durante tanto tiempo se haya pensado que el ojo tenía el poder de emitir un rayo luminoso. La óptica y la fisiología se demoraron mucho tiempo en "corregir" esta ilusión haciendo admitir que el ojo no haría sino refractar rayos luminosos que vienen del exterior. El sentido común, las creencias -que prefiero llamar representaciones culturalescontinúan resistiendo a esta corrección. Continúan pensando que algo sale del ojo y que el ojo es el soporte del poder de la mirada, que produce una astilla que brilla, una chispa (éclats), que no puede ser reducida a reacciones en la experiencia. Desde el punto de vista del inconsciente, esta resistencia del sentido común no es errónea. Es la razón por la cual Lacan compara el objeto $a$ con el seno o las heces, esas astillas parciales que caen del cuerpo y que permiten figurar dicho objeto. Como el Otro nos es inaccesible, nos contentamos con aprehenderlo a través de restos, a través de los desechos del Otro, que tienen la ventaja de testimoniar de su presencia. Tal es, en un cierto sentido, el objeto $a$, y la mirada es uno de los paradigmas mayores de este objeto (no me ocupo aquí del objeto $a$ en tanto vacío) ${ }^{7}$.

Estos desarrollos permiten entender que el estatuto de la Fantasma no es estrictamente el de una alteridad radical, de un Gran Otro, pues el sujeto se enfrenta con un objeto imaginario, con la mirada. Pero la mirada funciona aquí como éclat de otro, el signo de la presencia de un espíritu al que el sujeto no tiene acceso sino a través de un resto, una mirada que lo petrifica de espanto. El encuentro del Gran Otro, en tanto tal, está barrado para el sujeto, pero este lo intenta a través del indicio de la mirada. En este indicio, el sujeto imagina un goce de ese Otro, ve un exceso pulsional, una

\footnotetext{
${ }^{7}$ Hay que tener en cuenta tres aspectos para captar el estatuto del objeto a: astilla (éclat), resto y vacío: Lacan piensa que no nos formamos una idea del objeto a sino a través de sus astillas que podemos figurar en los objetos parciales de la succión, de la excreción, de la mirada y de la voz (Kaufmann, P. 1993). Estas serían las astillas (éclats) que se separan y caen del Otro. Pero el objeto $a$ no se reduce a esta lista. Sin contradecir esta definición se lo puede elaborar también como vacío, lo que plantea el problema de comprender qué puede querer decir el vacío como objeto. Convergentemente con esta paradoja, Lacan elabora la cuestión del resto: el objeto a sería un objeto originario, perdido, no accesible a la representación, pero que tendría efectos en el sujeto, de tal suerte que no parece siempre estar tan bien perdido. Además, el que esté perdido no significa necesariamente que el objeto $a$ haya alguna vez sido alcanzado o tenido (Baudry, 1993).
} 


\section{Mauricio García Peñafiel}

perversión del deseo, una plenitud, una fuerza, una condición ardiente y quemante que lo toma.

Si este objeto, y la Fantasma en particular, nos parece semejante a la madre arcaica, a la madre devoradora (Paulme, 1976; Cardiloni \& Nobili, 1977), es tal vez porque la relación con la madre aparece como el punto donde esta instancia del gran Otro va a formarse. Pero por su inserción en la ley del significante, el ser humano pierde el acceso a este objeto originario de lo maternal arcaico, que Lacan llama a veces la "Cosa". En consecuencia, el goce de/con/por la Cosa está barrado para el sujeto, perdido, y así este tiene acceso al goce fálico en la medida en que la castración es operada. Sin embargo, la clínica analítica y las víctimas del susto, nos indican que este goce de la Cosa sigue siendo buscado a través de los intentos por encontrase con el objeto $a$, lo que es narrado en el susto como el surgimiento del encuentro de una mirada. El hecho que los pacientes asustados sufran frecuentemente de impotencia sexual indica que porque han girado hacia el régimen del goce sin más, encuentran dificultades en el plano del goce fálico. El goce al que giran pareciera pulsar en la dirección de hacer Uno con el otro materno, como si el sujeto buscara aún ser el objeto del deseo de la madre ${ }^{8}$. Es lo que dice Gabriel, un paciente, quien después de un largo recorrido asociativo, pone en relación el encuentro con la Fantasma con recuerdos de la escena primaria, donde le impresionó constatar que su madre no sufría durante las relaciones sexuales con su padre, como había imaginado, sino que gozaba. La idea de que la avidez de la madre podría matar al padre se inscribió en Gabriel, lo que se hallaba sostenido por la fantasía edípica de disponer de su madre para él solo. Así, él sería el exclusivo objeto del deseo de la madre. Pero esto tenía un lado amenazante que retornó en el encuentro con la Fantasma.

Ahí donde la mirada de la Fantasma desea radicalmente, excesivamente al sujeto, este responde ofreciéndose como objeto de dicho deseo, disponiéndose a ser devorado. Pero al mismo tiempo, la víctima del susto testimonia que sabe del riesgo de desaparecer como sujeto si se deja ir hacia esa posición de objeto del deseo del Otro, sabe que corre el riesgo de hacer una ida sin vuelta. Esta es la razón del Espanto, que no es un simple miedo, puesto que está en juego la sobrevivencia psíquica del sujeto. Así, es el susto y sus síntomas los que revelan al sujeto lo imposible de gozar, el espanto es al fin de cuentas una manera de protegerse, una manera de decir «no» al deseo de ese Otro de lo materno. Es por esto que se entiende que el susto no

\footnotetext{
${ }^{8}$ Este empuje a querer devenir el objeto del deseo de la madre, Lacan (1988) lo teoriza como una identificación al falo de la madre. Más que ser satisfecho, el infans buscaría ser deseado, deseado por el deseo del Otro. Buscará ocupar un lugar en el deseo del Otro, lugar de objeto que Lacan llama "falo". Dicho de otro modo, para colmar su deseo de reconocimiento, el niño se propondrá, se ofrecerá como objeto; lo que deberá ser señalado como un imposible para que pueda devenir sujeto (En particular ver los capítulos : "La logique de la castration", pp.143-250, y "La signifiance du phallus", pp.251-354).
} 
sea solo maléfico para los implicados, sino también benéfico. Las parálisis, el mutismo transitorio, los sudores, los insomnios, la angustia permanente, etc., son todas formas de retornar a la condición de sujeto en falta. La expresión popular «curado de espanto», indica que el espanto opera también bajo la lógica de una vacuna, de tal suerte que la víctima del susto será más «fuerte» puesto que habiendo aproximado el goce pudo resistirle, logrando regresar, volver, de ese encuentro con el Otro.

Si la descripción imaginaria de la Fantasma como vieja madre devorante tiene tanta pregnancia en el discurso, si suscita tantas formas de angustia de castración, como la figura de la vagina dentada soñada por un paciente asustado, es porque la angustia de castración funciona como puerta de entrada y de salida respecto al régimen del deseo en tanto limitación del goce. $\mathrm{Al}$ respecto Gerard Pommier (1989) escribe:

A partir del miedo a una desintegración primera, que se muestra frecuentemente en el miedo a ser devorado, podemos comprender como se abre esta puerta de entrada que viene de nada, formando el acceso al goce fálico por las vías simultáneas del sexo, el síntoma y la implicación en la lengua. Esta 'entrada' en el falicismo depende de la angustia de castración, en la medida en que el cuerpo en su totalidad, tomado como falo imaginario de la madre, sufre esta amenaza. (p.275)

La lógica del susto sería entonces al menos doble. Deslizamiento hacia el goce junto con negación y rechazo de este. La misma estructura encontramos el considerar el estatuto de la Fantasma: no sería exacto decir que es una representación de gran Otro, puesto que hay del otro imaginario en ella. En buenas cuentas el susto articula el empuje al goce con la castración, el exceso y la falta. Es un proceso complejo el susto, y este dejarse ir hacia el goce articulado a su rechazo, da cuenta de la vivencia de fascinación y espanto frente a la mirada de la Fantasma.

La búsqueda de espacios de palabra que caracteriza a las víctimas de susto, que van a buscar interlocutores al bar, a la iglesia o a otros lugares, muestra que se esfuerzan insistentemente por despegarse del régimen del goce, puesto que la palabra intenta "reobtener" el goce con los instrumentos que señalaron su perdida. Hablando, la víctima llega lentamente a operar una suerte de desvanecimiento de la seducción de la mirada y de la imagen, ya que narrando una y mil veces sus infortunios, va introduciendo lo simbólico en su experiencia. En el mejor de los casos, el sujeto renunciará a encontrar las palabras justas para enunciar este encuentro, el cual debe quedar como indecible. En síntesis, la experiencia del susto contiene una lógica paradojal, pues se trata de un encuentro esperado ya que fascinante, pero que debe ser errado, perdido. El espanto es una trinchera cultural contra el deslizamiento del sujeto al régimen del goce. Esta lógica paradojal es homóloga a la lógica 
del Fantasma, la que marca la necesidad de realizar un encuentro, marcando al mismo tiempo la necesidad de errar su actualización. Esta articulación es condición de su eficacia (Calligaris, 1983).

Freud pensaba que el «ballet» histérico era una manera de traspasar el efecto de la seducción al otro. La histérica enviaría al otro la petrificación de la seducción, dejándolo en un estado entre la angustia y el placer. La víctima del susto no procede de este modo, acarrea consigo el efecto de la seducción de copa en copa y de bar en bar. Le es imposible traspasar a otro su espanto. Beber alcohol, «algo para limpiar el corazón»-como decía uno de mis pacientes- será la tentativa espontánea para deshacerse de esta intrusión. El drama de la seducción reposa en el hecho que el que mira es aspirado por una imagen que le arranca los ojos. Es imposible, dice el discurso, mirar a la Fantasma y recuperar la propia mirada, ya no se la puede repatriar en el ojo. La mirada expatriada conlleva esa alienación y pérdida fundamental que los pueblos prehispánicos llamaban «pérdida del alma», que era como entendían los Quechuas el Susto (Arias-Schreiber, 1987). Esto nos hace ver que en el susto no es solamente cuestión de pérdida de la motricidad o del habla. Estos síntomas están ahí para hacer escuchar un escurrirse de la subjetividad como lo significan las expresiones «cagarse de susto» y «mearse de susto»que dirigirá al sujeto hacia una tentativa de recuperación a través de la incorporación de un fluido. Pero no cualquier fluido, se trata de un alcohol con referencias rituales en la tradición popular: pisco, agua ardiente o vino. El problema del alcoholismo, a veces subsecuente al susto, se debe a la imposibilidad de regular la cuestión de la dosis, en la medida que el contexto cultural actual no logra ofrecer un cuadro para la incorporación ritual eficaz ${ }^{9}$.

Con el alcohol algunos pacientes buscan «limpiar el corazón», pero otros buscan recuperar la capacidad de verse interiormente, de reencontrarse. Un paciente habla del alcohol como un espejo. En ese intento por reconstruir su subjetividad el pisco funciona como un operador que le permite ver de nuevo lo que ha sido perdido. El alcohol le permitiría recuperar lo que ha sido extraviado en la Fantasma. Sería un medio de ver algo más que esa pura mirada, una estrategia para despertar la intimidad de una manera más intensa, de lo cual la «confesión» en los bares es el signo más evidente. Beber alcohol, sería como incorporar una sonda, con la cual el sujeto puede reencontrarse, y bajo cuyo efecto se pone a hablar, se le «suelta la lengua», sobre todo en los núcleos conversacionales y confesionales que estructuran al bar popular, y solo después, eventualmente, en el consultorio

\footnotetext{
${ }^{9}$ Este problema de la pérdida del «encuadre» ritual ha sido identificado como factor importante del aumento de adiciones en otros países (Gueye \& Omais, 1983). Estos hallazgos al menos «muestran», sino demuestran, que el valor terapéutico no está en los objetos (ni en las substancias) desprovistos del universo simbólico que los hace significantes.
} 
«psi». Soltando su lengua con el vino o con el pisco, el sujeto busca soltarse de la Fantasma, desatarse de la seducción de la mirada que miró.

\section{Conclusiones}

En cierto sentido la víctima de susto encuentra un objeto que de alguna manera es él mismo, mira y es mirado por un Otro que lo constituye. La lección a escuchar pienso que es que la seducción operada por la mirada, por la fascinación de la mirada, es ante todo una seducción por si mismo por intermedio del otro. Seductor y seducido son actores inscritos en la misma escena. El otro es el espacio de rodeo del objeto deseante, que pena en el psiquismo de todos. El concepto psicoanalítico de "Fantasma" es particularmente útil para aclararnos que el encuentro de otros, múltiples y diferentes en cuanto al estatuto de su alteridad, se anuda siempre con un encuentro primero, que marca la relación de alteridad como tal y los encuentros posteriores.

Me parece fundamental recalcar la resistencia al goce del Otro operada por el discurso. Dicha resistencia se marca con la prohibición de mirar y también con los síntomas del susto, que son la negación que el sujeto hace el deseo del otro. Aunque estos discursos indican la imposibilidad de resistirse a la fascinación de la mirada, señalan un medio para salir de la fascinación. Y el que sale devendría más "fuerte", "curado de espanto". ¿Cuál es la naturaleza de la supuesta fuerza que el sujeto adquiere? Creo que es una fuerza que tiene que ver con el saber, con un cierto saber sobre el goce. Aquel que se sumerge en la fascinación de la mirada y logra no hundirse hasta la muerte (como fue el destino de narciso) deviene más fuerte porque se ha mostrado capaz de resistir al goce.

Tal vez un breve paralelo mitológico permita desarrollar esta idea. Me refiero a las pruebas que Ulises debe enfrentar en la Odisea. Ulises es confrontado muchas veces a la mirada, pero para ilustrar esta resistencia al goce, resulta más contundente referirse al conocido episodio en que es confrontado a las voces de las Sirenas. Habiendo sido advertido sobre los peligros de dejarse llevar por la fascinación de los cantos de las Sirenas, Ulises toma firmes precauciones para su tripulación. Todos debían tapar sus orejas con cera, salvo él, que a partir de una invitación de Circe, se reserva el derecho de someterse a la prueba. Solo su oreja tiene el derecho de exponerse a esta prueba de goce y de muerte. Pero Ulises conoce los riesgos y toma la precaución de hacerse atar, para estar impedido de ir hacia la fuente de las voces. Tenemos aquí una imagen fuerte del maestro, trabado pos sus propios subordinados. Ulises está fijado al centro del riesgo. De alguna manera está crucificado en el mástil para enfrentar la prueba del goce. Él puede hacerlo, ya que tiene los medios de resistir sin volverse loco, y tiene el derecho de degustar y probar. El heroísmo de Ulises se juega, paradojalmente, en una transgresión exitosa. De hecho saldrá religitimado de 
la prueba. Aquellos que se taparon las orejas no tiene el mérito de haber resistido a la tentación, mientras que él se reafirma como maestro pues sabe a qué hay que resistir por el hecho de haberlo experimentado. Es justamente porque renuncia al goce, aun habiendo probado y degustado, que puede ser puesto en el lugar del «piloto». Él podrá entonces regir mejor el deseo de los otros por haberse confrontado a este desafío mortal.

Desde el punto de vista de la terapéutica, me parece relevante comentar la dimensión de búsqueda ritual que hay en el susto, en el modo de agenciar el espacio-tiempo del bar y estatuto del alcohol, a través del cual el sujeto busca "curarse". Más allá de reconocer allí "restos" de antiguos ritos populares o indígenas, me parece que el discurso, aún vivo, persiste en situar a las víctimas de susto en una demanda de ritualidad que se instala en el dispositivo terapéutico. Esto me parece que ocurre también con otras "enfermedades populares" en distintos lugares de América Latina. Junto a la eventual demanda de ritualidad, me parece importante indicar que estos discursos tienen una dimensión pragmática, esto es: más que tener por función significar algo, al narrarlo el sujeto se hace algo a sí mismo. Al pensarse como poseído por ejemplo, evita caer en la melancolización que acarrea pensarse vacío o víctima de una pérdida. Desde este punto de vista valdría la pena considerar estas narraciones como portadores de ciertas "estrategias narrativas", que nos confrontan con la pragmática del narrar, nos exigen entender que nuestros pacientes junto con enunciar su sufrimiento "hacen algo" en el acto de narrar.

Las narraciones no son colecciones de hechos o de cosas exactas, son "hechos de significación" (Adam, 1990), en la medida que se actualizan como un sistema para dar sentido y que extrae estos sentidos de la masa caótica de percepciones y experiencias de la vida. Incluso el estudio más cercano y detallado de la subjetividad, como un psicoanálisis, no es una excavación arqueológica -incluso si este modelo era caro a Freud- sino una verdadero "paseo en una historia reformulada, a la búsqueda de etapas de vida, con el fin de ayudar lo mejor posible al sujeto en el presente" (Josselson, 1998, p.895).

Tal vez las narraciones, eso que llamamos cuentos populares, leyendas o mitos, son -o más bien siguen siendo- un espacio posible de encuentro entre palabra y rito. A través de su enunciación algo es hecho e instaurado, al modo del performativo de Austin (1970). La insistencia popular en reapropiarse sin cesar de estos discursos es no solo un modo de transmitir la historia social, sino también un material a través del cual el sujeto puede insistir en operar pragmáticamente sobre sí, a través de una praxis del narrar. En paralelo con esta hipótesis, vale la pena reparar en que el espacio más relevante de enunciación de nuestra identidad es la literatura latinoamericana y no nuestras ciencias sociales. Y esta literatura frecuentemente se constituye escribiendo las narraciones que circulan en la cultura. 


\section{Referencias}

Adam, J. (1990). Aspects du récit anthropologique. En: Adam, J-M. Le discours anthropologique, Paris: Méridiens Klincksieck.

Arias-Schreiber, M.P. (1987). Susto ou le vol de l'âme. Métaphores corporelles dans le cadre d'un désordre ethnique.: Nouvelle revue d'ethnopsychiatrie, 8/9, 123-137.

Austin, J. L. (1970). Quand dire c'est faire. Paris: Seuil.

Baudry, F. (1993). Objet. En: Kauffmann, Pierre: L'apport Freudien. Paris: Bordas, pp.281-283.

Calligaris, C. (1983). Hypothèse sur le Fantasme. Paris : Seuil.

Cardiloni, G. \& Nobili, D. (1977). La manvaise mère. Paris: Payot.

Devereux, G. (1977). Essais d'ethnopsychiatrie générale. Paris : Gallimard.

Freud, S. (1909/1997): Lo ominoso. En: Obras Completas. Buenos Aires: Amorrotu, vol. 17, pp. $215-251$.

Flavigny, C. (1987). De la perception visuelle au regard. Nouvelle Revue de Psychanalyse, n³5.

Frontisi-Ducroux, F. \& Vernant, J-P. (1997). Dans l'ail du miroir. Paris: Odile Jacob.

García, M. (2000). La perte et le deuil déguisés en possession: considérations ethnopsychanalytiques sur la maladie du susto au Chili. En: Weil, Dominique: Mélancolie: entre souffrance et culture. Strasbourg: Presses Universitaires de Strasbourg, 141-166.

Gueye, M. \& Omais, M. (1983). Tentative pour une approche socio-culturelle de l'usage abusif de drogues au Sénégal. Psychopathologie Africaine, 19(2), 141-172.

Israel, L. (1994). Le désir a l'oeil. Paris: Arcannes.

Josselson, R. (1998). Le récit comme mode de savoir. Revue Française de Psychanalyse, 3, Tomme LXII.

Kaufmann, P. (1993). L'apport freudien. Paris: Bordas.

Lacan, J. (1988). Le Séminaire, Livre V. Les formations de l'inconscient. Paris: Seuil.

Lacan, J. (1991). Le séminaire. Livre VII. Le transfert. Paris: Seuil.

Loraux, N. (1982). Ce que vit Tiresias. L'écrit du temps, nº2.

Nathan, T. (1994). L'influence qui guérit. Paris: Odile Jacobs.

Paulme, D. (1976). La mère dévorante. Paris: Gallimard.

Pommier, G. (1989). L'ordre sexuel. Paris: Aubier.

Simon, G. (1988). Le regard, l'être et l'apparence dans l'optique de l'Antiquité. Paris: Seuil.

Vicuña Cifuentes, J. (1947). Mitos y Supersticiones. Santiago de Chile: Nacimiento.

Recibido: 26 de octubre de 2010

Aceptado: 14 de noviembre de 2011 